\title{
My career as a cardiologist and the developmental history of coronary intervention in Japan
}

\author{
Masakiyo Nobuyoshi
}

Published online: 17 June 2010

(C) Japanese Association of Cardiovascular Intervention and Therapeutics 2010

In 1978, I attended the AHA annual meeting in the United States where I heard about PTCA (percutaneous transluminal coronary angioplasty) for the first time through Dr Gruuetzig's poster presentation. Many cardiologists crowded around his presentation with intense scientific interest. At that time, I already had abundant experience in diagnostic coronary angiography and it concerned me that new therapeutic options were quite dangerous as coronary intervention might damage vessel intima and cause an intravascular clot. Between 1979 and 1980, PTCA gained wide acceptance in the United States with favorable results which prompted me to initiate this new promising therapy in Japan.

In 1981, Dr Simpson came over to Japan to give a lecture on methods of procedure using the Simpson and Robert balloon catheter. Although dealing with the balloon catheter seemed rather complicated, I decided to perform my first case in Japan in October of 1981.

It was an unforgettable day for me. I asked the cardiac surgeons to wait ready for emergency cardiac bypass surgery just in case. It was a simple, type A, LAD lesion. I failed, and the patient unfortunately underwent an emergency cardiac bypass surgery. I did two cases in succession with dismal failure requiring emergency bypass surgery. Dr Ban, Chief of Cardiac Surgery at Kokura Memorial Hospital at that time, was furious with me saying that this crazy therapy should be suspended. I became painfully aware that I needed to work up the technique of PTCA, thereafter I visited several famous institutes in the United

M. Nobuyoshi $(\square)$

Kokura Memorial Hospital, Kifune-cho, Kokurakita-ku,

Kitakyushu, Fukuoka 802-8555, Japan

e-mail: noda-k@kokurakinen.or.jp
States. I went across the Pacific almost twenty times to visit "PTCA gurus" at that time, e.g. Dr Richard Myler at Seaton Medical Center, Dr Simpson at Sequoia Hospital, Dr Dorros, Dr Hatzler and many more. I took very precise notes about the details of the procedure-how to deal with a balloon catheter or how to advance the guidewires etc. In 1982, I performed a 4th PTCA case which yielded a first success at Kokura Memorial Hospital.

Even after the first success case, I kept visiting the United States, especially Dr Hatzler's hospital, to learn his technique of manipulating guide wire quickly and accurately. It is not too much to say that Dr Hatzler made me what I am today.

I performed ninety-three cases per year in 1983, and was able to perform forty cases per week in 1984. Thousands of doctors packed into the cath lab in my hospital every day. It became physically difficult to teach my technique to all the visitors, and I held the first live demonstration in 1984 with TV transmission between Hospital and Medical Association Hall. At that meeting, I invited Dr Dorros from the States and performed ten PTCA cases per day with him before an audience of about 300. This Live Demonstration has been held every year.

Although live demonstrations provided an excellent opportunity to teach procedures, it left little time for scientific discussion, which urged me to set up a scientific meeting of PTCA. In 1985, we held a first workshop of coronary angioplasty at Kokura. We put together all the presentations, materials and discussions in book form with the future possibility of transforming into an academic society.

The workshops were held for seven consecutive years, leading to the foundation of the Japanese Society of Interventional Cardiology (JSIC) in June, 1992. I was assigned as the first president. Several years after the 
foundation, the idea of JSIC had changed its nature as compared to its original form. Subsequently, I founded a new society, the Japanese Association of Cardiovascular Catheter Therapeutics (JACCT), with several colleagues with a core idea of $3 \mathrm{~S}-$ simple, speedy, safety. Both the JSIC and the JACCT had developed and flourished with a good competitive relationship. Due to fluctuation of their associates, both societies were eventually consolidated to set up the Japanese Association of Cardiovascular Intervention and Therapeutics (CVIT) which is a fascinating society since it includes all the professionals involved in cardiovascular interventions in Japan. I am very honored to be involved and will give my full support for the further development of this society.

My best wishes for CVIT's future growth and prosperity. 